\title{
Research on Training Mode of Improving College Students' Innovative and Practice Ability
}

\author{
W.B. Zhu, H.X. Liu, T. Jin \\ Office of Educational Administration \\ Tianjin Agricultural University \\ Tianjin, China
}

\author{
L. Huang \\ College of Agronomy \& Resources and Environment \\ Tianjin Agricultural University \\ Tianjin, China
}

\author{
J. Liu, X. Sun* \\ College of Biological Engineering \\ Tianjin Agricultural University \\ Tianjin, China \\ *X. Sun sunxiaoxisunxiao@163.com
}

\begin{abstract}
Innovation is the soul of a nation. Universities shoulder the historical mission of developing students' innovative capacity. Research on training mode of improving college students' innovative and practice ability has become a hotspot in reform of higher education. In this paper, we analyzed the factors influence the originality of students, and found that innovation ability includes three parts: the innovative knowledge, the innovation ability and the innovative character. Among the three parts, the innovative knowledge includes the capacity of the knowledge and the knowledge structure; the innovative ability includes the ability of learning, observing, finding, organizing and solving problems; the innovative character consists of the moral traits and the personal features. The three components form a Trinitarian relationship and wield "foundation", "base" and "direction" effects on engineering college students respectively. The three components interact and supplement with each other, and form a circling system that runs smoothly. On this basis, we explored the training mode to improve innovation and practice ability of students in agricultural university.
\end{abstract}

\section{Keywords_-innovation; practical ability; training mode}

Science and technology is the first productive force, and innovation is an inexhaustible motive force for the prosperity of a country [1]. To cultivate and improve the innovation ability of college students is an important embodiment of the call of the times and to meet the needs of people's development [2,3]. Therefore, it is a close to improve the effectiveness of College Students' innovation ability to build a good training mode of College Students' innovation ability. The research on this aspect is an urgent requirement of the development of higher education, which has far-reaching significance

\section{ChinA's CURRENT StATUS OF Agriculture UNDERGRADUATE TRAINING}

\section{A. Selecting a Template}

Early Chinese University Education in the use of the former Soviet Union concentrated force of running a school, training elite school model, detailed division of the professional and field [4,5]. With the deepening of education, China's own university education system has been gradually perfecting. This mechanism of our current system of university education plays an important role in the training of personnel for national economic construction, but appeared some outstanding problems also. Some domestic entrepreneurs and foreign experts generally believe that the basic skills of Chinese students is relatively solid, but the practice ability is not strong, as well as their innovative awareness [4]. Our survey to agricultural college students also found that students generally believe that they have to strengthen the ability of training, find problems from practice, and improve their ability to innovate [5].

\section{Factors Affecting College Students' Creative ABILITY}

Innovation ability is not innate, not acquired in the culture overnight. Its prerequisite is that the creator has the ability to use the existing knowledge, information, skills and methods to put forward new problems and new perspectives, which can be seen, the spirit of innovation is actually a diverse complex.

As it shown in Fig. 1, students' innovative practical ability depends on the cooperation of 'student, teacher and school' three important elements. The cultivation of students' innovative practical ability cannot depart from the support of school and teacher's teaching. Based on perfecting themselves, the influence of environment is very important. Knowledge is critical for the formation of innovation ability; it can also decide the level of the ability; in the formation of individual innovation ability play a role of learning about the world. Cannot make bricks without straw', the establishment of the school platform is significant to improve students' innovation ability. Many schools' hardware is the main factor that limits students' innovation ability. Through using the platform from school and the knowledge taught by their teachers, students integrating their own new ideas and new opinions, discovering 
problems, analyze and solve them. Efforts to improve their own quality, namely improve the innovation ability in practice.

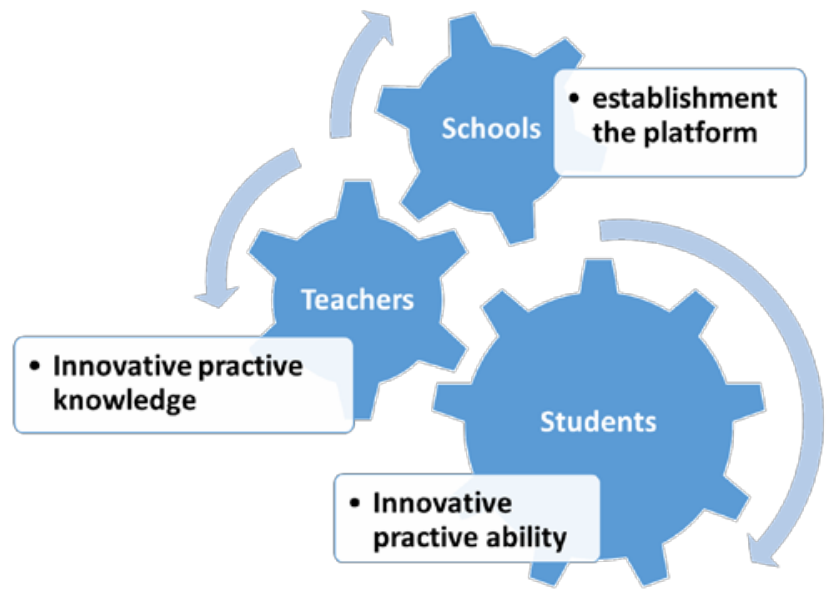

Fig. 1. The three key elements in cultivating students' innovative practice ability

The reason of Chinese undergraduates lacking innovation spirit and weak in practice ability can be discussed from the following three aspects.

\section{A. Passivity for Innovation Because of the Deficiency of the Traditional Education Mode}

As we all know, Traditional education methods focus on knowledge infusion, in which teacher is not only the performer of the teaching task, but also the dominant, students in a passive position, only to accept not to create. The autocracy teaching mode obscures the differences of students' learning characteristics and cognitive, suppress the personality of students, lead to students' low innovative ability [6, 7].

\section{B. Excessive Pursuit for High Scores Leads to Students Lack the Spirit of Innovation}

The pursuit of high scores in the examination-oriented education results in the rigid thinking. Instead of exploring the possibility of a variety of answers, students are accustomed to looking for the "only right" answer. In this fixed mode of thinking, students are no longer looking for a difference, lacking of innovative spirit.

\section{The Lack of Practical Teaching Conditions Leads to the Absence of Practice}

Traditional teaching pays more attention to theory, and often ignores the importance of practice, coupled with the lack of investment in education funding, leading to the construction of practical training base relatively behind. As a result, graduate students' low level of practical ability cannot meet the job requirements of the enterprise employment.

\section{DiscusSiOn IN TRAINING MODES TO IMPROVE THE STUDENTS' CREATIVE AND PRACTICAL ABILITY}

\section{A. Changing Concepts of Education and Reforming the Traditional Education Mode}

These ways, improving understanding, changing concepts of education, changing the teaching mode of teacher-led classroom, taking the students as the dominants and following the "student-oriented" principle of education are essential for education reformation. The specific methods to cultivate the innovative ability are using innovative teaching methods, using innovative teaching methods, the construction of practice teaching, establishing practice platform, establishing efficient innovation ability training security system and so on.

\section{B. Improve the Evaluation System and Establish Appropriate Evaluation Methods}

Students in the university learning is not in the traditional sense of acquiring knowledge, but acquiring ability of problem analysis and problem solving to better survive in the society and to have a better life $[8,9]$. The organic integration of the elements of the undergraduates' innovative ability training mode is organically integrated so that the elements come into an effective operating mechanism, optimize the existing main training mode, and improve the effectiveness of the innovation ability training. Instead of the result of high score and low abilities, the goal of higher education is to cultivate and improve the ability of knowledge learning, ability to apply, ability to judge, integrate ability and create ability, so as to cultivate and improve students' ability to innovate.

\section{Extend the Students' Interests and Hobbies}

Student potential and creativity is unlimited, keep an open mind and open academic vision is very important [10]. Due to the inertia of professional education for a long time, teachers and administrators in colleges and universities find it hard to get rid of the influence of the paradigm of academic disciplines. In the process of organizing undergraduates to carry out scientific research activities, consciously or unconsciously according to existing mindset and study mode to operate. The undergraduate innovative entrepreneurship training is not enough and there existing a serious gap between theory and practice.

Take interest as a starting point, students are encouraged to do something unconventional or unorthodox, let students dare to think, dare to do, can write, can speak. Continuously stimulate students' interest in learning, exert the students' creative potential, to achieve to cultivate the students' innovative spirit and entrepreneurial ability, make the student's knowledge internalizes as their own quality, externalizes as their ability.

\section{Strengthen Resources Guarantee and Conditions Created}

1) The basic guarantee of teachers of the basic faculty

Personnel training mainly depend on education, innovative personnel training depends on innovative education, but the innovative education development mainly relies on the quality of teachers. Reduce large classes as forms of education, which 
lack of communicate opportunities between teachers and students, to implement small class teaching, teaching assistant system and so on. Don't too dispute in the protection of teachers in teaching cost, to further increase the number of hiring teachers; at the same time hold good teachers, optimize the teachers learn as much as possible academic structure and professional structure; also pay attention to the continuing education of teachers, explore the implementation of higher engineering education teacher certification system; it is necessary to pay attention to the cultivation of new teachers, but also pay attention to existing teachers do to maximize creativity.

\section{2) Equipment facilities and student innovation platform}

Specifically includes two aspects: First, the hardware construction, mainly to increase investment, the library, experimental teaching center, scientific and technological innovation center and Laboratory and other resources such as high-standard construction. The second is the construction from the software, including increased management and are open to these facilities and platforms as well as to enhance students' ability and efficient use of resources, innovative science.

3) Increase financial support, to provide comprehensive and timely guidance

To complete an innovation activity, the relevant research equipment purchase and development, information retrieval and purchase, papers published, and an application for a patent all of them need financial support, we can set up a special fund for college students' innovation, to provide fertile soil for the student innovation teams. By creating the carrier of students under the guidance of teachers, such as scientific research training program, the tutorial system, and strengthen the policy levers, encourage teachers to participate in the guidelines for the students.

\section{E. Strengthening the Construction of Practical Teaching Base and Improving the Quality of Practical Teaching}

"What's learned from books is superficial after all”, especially for the agricultural students, no experience is difficult to grasp the knowledge points on the books, such as crop breeding experiments, the process of how to pollination. If students do not personally practice, it is difficult to understand theoretical knowledge. In addition, it is not enough to simply the experiment that has been set up the experiment purpose, procedure and conclusion already in the book. In order to develop creative thinking, eliminate the mindset, students need to think about themselves, to verify and solve their own questions. Therefore, the University of Science and engineering laboratory should be more open to students, the experimental teacher just guiding from the side, not to command and supervise. At the same time, a comprehensive innovative experiment is added in the experiment course to change the situation that was mainly based on the verification experiment in the former. For example, "Food technology big experiment", "Biotechnology big experiment" and so on in our school has effective inspired and cultivated students' innovative thinking.
At the same time, in recent years, the national organization of College Students' innovation and entrepreneurship training project also has a significant effect on the cultivation of College Students' innovative and entrepreneurial ability. Undergraduates find problems through their own research, systematically to solve the problem with the guidance of the teachers, finally to report project and write papers, and even to apply for a patent for invention. In 2015, a total of 49 projects were titled to national innovation and entrepreneurship training programs in our school, including 5 entrepreneurial practice projects, and 83 projects were awarded as Tianjin municipal college students innovation and entrepreneurship training programs, 170 articles were published, 127 among them were students to be the first author, 22 patents, 3 application software copyrights, 11 Student Competition Awards. Students' innovation and entrepreneurship training program provide students with a good platform, while only graduates could complete a research systematically in the past. In fact, in undergraduate education, it is also necessary to take scientific research as the carrier to involve undergraduates and gradually cultivate the students' innovative spirit and creative thinking. The participation experiment can stimulate students' interest and initiative. At the same time, knowledge has been strengthened and it's more convenient for teachers and students to communicate.

Therefore, to improve the students' ability of innovation and practice, we need to set up with the following aspects: getting the frontiers knowledge, cultivating students' learning ability and a flexible application of knowledge, cultivating college students to observe and understand the problem, cultivating College Students Analysis and judgment ability, constructing efficient platforms for practice, cultivating college students' ability to comprehensive use of knowledge , training students' innovation ability of knowledge integration, and ultimately the formation of the innovative ability training mode.

\section{CONCLUSION}

We should concentrate on practical teaching, giving full play to the role of the practical teaching, which is a important way to train the innovation ability of the college students under the condition of market economy system. Through years of exploration and effort, handing ability of our agricultural professional graduate has won the acceptance of employers. Because the reform of professional practical teaching is still on the way, we will continue to summarize the experience in the practical teaching and strengthen the training of student's innovation ability to cultivate high-quality innovative talents.

\section{REFERENCES}

[1] J.C. Yu, "Exploration and Practice on Cultivating Student' Experimental Ability Depending on Experimental Teaching Demonstration Center," Experiment Technology and Management, vol.30, pp.117-119, 2013.

[2] X.F. Lu, P. Wang, P. Luo, et al, "Enhancing Construction of Experimental Teaching Demonstration Center and Cultivating Students' Innovation Capacity,” Experiment Technology and Management, vol.30, pp. 95-98, 2013.

[3] H.Y. Mao, Z.P. Wang, “Tourism Management Professional Training Mode Innovation,” Asian Social Science, pp.1911-2017, 2010. 
[4] Y. Song, X.B. Xu, “A Study on Construction and Effect Experimental Teaching Demonstration Center for Plant Production,” Experiment Technology and Management, vol.30, pp.109-111, 2013.

[5] J. Cheng, F. GAO, "Exploration and Reflections on Construction of Experimental Teaching Centre in Colleges and Universities,” Research and Exploration in Laboratory, vol.31, pp.101-102, 2012.

[6] J.H. Hu, Y.Q. Zhang, “College Innovative Talents Training Mode Based on Practical Teaching Reform,” Springer Berlin Heidelberg, 2013.
[7] H. Zhu. "An Exploration of Innovative Talent Producing Mode in Colleges and Universities,” Journal of Higher Education Management, 2008.

[8] H. GUAN, Y.G. LI, "Manpower Planning On Mechanical Innovative Talent,” Journal of Dalian University, 2009-06.

[9] C.W. WANG, O.Y. QIONG, "The Construction and Practice of New Education Approach in Colleges of Engineering," Higher Education in Chemical Engineering, 2008-05.

[10] H.P. SHEN, “An Investigation of Mechanical Creative Design,” Mechanical Science and Technology, 1997-05. 